\title{
A biomimetic synthesis of stable gold nanoparticles derived from aqueous extract of Foeniculum vulgare seeds and evaluation of their catalytic activity
}

\author{
Manoj Kumar Choudhary $^{1} \cdot$ Jyoti Kataria $^{2} \cdot$ Shweta Sharma $^{3}$
}

Received: 17 June 2017/Accepted: 19 August 2017/Published online: 28 August 2017

(c) The Author(s) 2017. This article is an open access publication

\begin{abstract}
A facile biomimetic approach for the synthesis of gold nanoparticles (AuNPs) using aqueous extract of fennel (Foeniculum vulgare) seeds have been reported in this article. The seeds of $F$. vulgare are rich in various plant secondary metabolites (phytochemicals) such as polyphenolic acids, flavonoids, and saponins. The phytochemicals of $F$. vulgare seeds play dual role of reducing and stabilizing agents. The formation of gold nanoparticles was evidenced from the appearance of intense purple color at room temperature with $\lambda_{\max }$ around $550 \mathrm{~nm}$ in the UV-Vis absorption spectra. The stable AuNPs were further characterized by X-ray diffraction (XRD), Fourier transform infrared (FT-IR) spectroscopy and transmission electron microscopy (TEM) analysis. The synthesized nanoparticles were observed to be polydispersed, spherical and ranged from 10 to $30 \mathrm{~nm}$ with an average size of $20 \pm 2 \mathrm{~nm}$, as obtained from TEM images. The catalytic activity of gold nanoparticles was investigated by studying the reduction of anthropogenic dyes such as methylene blue (MB) and rhodamine B (Rh-B) with sodium borohydride. Results
\end{abstract}

Manoj Kumar Choudhary

choudhary.nrl@gmail.com

Shweta Sharma

25shweta@pu.ac.in

1 Nanomaterial Research Laboratory, Department of Chemistry, Guru Nanak National College, Doraha, Punjab 141421, India

2 Department of Chemistry, Panjab University Research Centre, Goswami Ganesh Dutta S. D. College, Sector-32C, Chandigarh 160030, India

3 Institute of Forensic Science and Criminology, Panjab University, Chandigarh 160014, India showed the possible applications of biogenic AuNPs in environment related problems.

Keywords Gold nanoparticles - Biogenic synthesis · Catalytic reduction - Anthropogenic dyes · Fennel seed

\section{Introduction}

Several water soluble anthropogenic dyes are extensively utilized in various industrial processes such as cosmetics, textiles, printing, ceramics, pharmaceuticals and food processing (Kant 2012). For example, methylene blue, a thiazine dye, is readily used in textile, data storage and holographic industries (Rajesh et al. 2014). It is also utilized for staining tissues and body fluids during diagnosis and surgeries (American Pharmacists Association 2012). Moreover, it also has applications as anti-malarial agent and chemotherapeutic agent (Schirmer et al. 2003; Mwangi et al. 2016). Similarly, Rhodamine B, a fluorescent staining dye, has applications in the field of flow cytometry (Temmerman and Nickel 2009), fluorescence microscopy and ELISA tracer techniques (Shelley 1969; Forster et al. 2012). Further, it is also utilized as tracer for determination of transport and flow direction of water (Mull 1993; Hardy et al. 2016). All these processes, at various stages, require large quantity of water, and thus produce effluents which are fortified with various hazardous colorants. These waste water discharges with various dye stuffs lead to elevated demand of oxygen chemically as well as biologically (i.e., COD and BOD).

Most of the anthropogenic dyes are carcinogenic and mutagenic and cause high level toxicity to humans, aquatic organisms and whole eco-system. Therefore, the degradation of these dyes is important industrially and 
environmentally. Generally, coagulation, flocculation, adsorption, chemical precipitation and oxidation methods are employed for the removal of dyes. More recently, noble metal nanoparticles because of their enhanced catalytic activity and high stability have gained importance in the area of catalytic degradation of toxic coloring agents, such as dyes and pigments. For instance, the catalytic reduction and degradation of various dye pollutants using metal nanoparticles (MNPs) such as $\mathrm{Cu}, \mathrm{Ag}, \mathrm{Au}, \mathrm{Pd}$ and $\mathrm{Pt}$ has been reported (Gangula et al. 2011; Sahoo et al. 2014; Kumari et al. 2015; Yang et al. 2015). Various biogenic synthesis routes have been employed in the fabrication of noble MNPs using Cylindrocladium floridanum and Penicillium fungus (Sadowski et al. 2008; Narayanan et al. 2013), Vigna radiata seed extract (Choudhary et al. 2016), Catharanthus roseus leaf extract (Kalaiselvi et al. 2015), Solanum lycopersicums fruit extract(Umadevi et al. 2013), Cocos nucifera coir extract (Roopan et al. 2013), Artemisia nilagirica leaf extract (Vijayakumar et al. 2013), etc.

In this report, we have reported the phytochemical preparation of (AuNPs) utilizing aqueous seeds extract of Foeniculum vulgare (fennel seeds). Fennel is a flowering herbaceous plant which belongs to the Apiaceae family. The F. vulgare seeds are native to Southern Europe and popular as most sought-after ingredient in Chinese, Turkey, and Indian cuisines. The seeds of fennel are extensively grown in all over Europe, Middle-East and all over the Mediterranean regions for their distinctive sweet, aniseflavor. Moreover, the seeds of $F$. vulgare have been reported to exhibit antimicrobial (Purkayastha et al. 2012), antioxidant (Roby et al. 2013), antitumor, antiallergic and memory enhancing properties (Badgujar et al. 2014). The major phytochemicals present in the seeds are saponins, tannins, polyphenolic acids and flavonoids (Purkayastha et al. 2012).

The as-synthesized AuNPs were analyzed using various spectroscopic and microscopic techniques such as UV-Vis; TEM, XRD and FT-IR. Further, the AuNPs were employed as nanocatalysts for the borohydride reduction of MB and $\mathrm{Rh}-\mathrm{B}$. The catalytic reduction of these carcinogenic dyes was investigated periodically by studying their decline in intensity of absorption using UV-Vis spectroscopy.

\section{Experimental Section}

\section{Materials and methods}

Hydrogen tetra chloroaurate trihydrate $\left(\mathrm{HAuCl}_{4} \cdot 3 \mathrm{H}_{2} \mathrm{O}\right)$ of reagent grade was obtained from Sigma-Aldrich while methylene blue (MB), rhodamine $\mathrm{B}$ (Rh-B) dyes and $\mathrm{NaBH}_{4}$ for catalytic reduction reactions were purchased from Fisher Scientific, Mumbai. All solutions used in the synthesis procedure were prepared with double distilled water.

\section{Preparation of fennel seeds extract}

Foeniculum vulgare seeds were obtained from the super market of Ludhiana, Punjab, India. The seeds were washed with deionized water three times to remove any dust particles and left overnight to dry. $5 \mathrm{~g}$ of dried seeds were refluxed at $80{ }^{\circ} \mathrm{C}$ for $30 \mathrm{~min}$ in a 250 -ml Erlenmeyer flask containing $150 \mathrm{ml}$ of deionized water. After cooling, the aqueous extract was filtered through Whatman no. 1 filter paper and stored in refrigerator for future use.

\section{Biogenic synthesis of gold nanoparticles}

For synthesis of AuNPs using fennel seeds, first, $1 \mathrm{mM}$ aqueous $\mathrm{HAuCl}_{4} \cdot 3 \mathrm{H}_{2} \mathrm{O}$ solution was prepared by dissolving $98.5 \mathrm{mg}$ of $\mathrm{HAuCl}_{4} .3 \mathrm{H}_{2} \mathrm{O}$ in $250 \mathrm{ml}$ of deionized water and then gold solution and aqueous seeds extract in the ratios $(7: 3,8: 2$, and 9:1 v/v) were carefully mixed in three different $250 \mathrm{ml}$ flasks and labeled as FA-3, FA-2 and FA1 (where the number 3, 2 and 1 corresponds to volume of seeds extract). The flasks containing reaction mixture were stirred magnetically under dark with 700-800 rpm. During the course of reaction, the color of colloidal solution was changed from yellow to purple which indicated the formation of AuNPs.

\section{Characterization of biogenic AuNPs}

\section{$U V-$ Vis spectroscopy}

The periodical monitoring of AuNPs formation at a regular interval of $15 \mathrm{~min}$ was carried out using Shimadzu 2550 UV-Vis spectrophotometer. An intense peak around $540-550 \mathrm{~nm}$ in the visible region was observed which corresponds to surface plasmon resonance (SPR) absorption of nanogold. To investigate the stability of the biogenic AuNPs, the $\lambda_{\max }$ value was also recorded after $24 \mathrm{~h}$. For analysis, $0.3 \mathrm{ml}$ of colloidal AuNPs solution was withdrawn and diluted to $3.0 \mathrm{ml}$, by adding deionized water in a quartz cuvette. The SPR absorption of AuNPs was recorded in the wavelength range between 250 and $800 \mathrm{~nm}$.

\section{FT-IR spectroscopy}

The involvement of active molecules of fennel seeds in the reduction and capping of NPs were determined using Perkin Elmer RX-I, FT-IR spectrophotometer. The dried extract and synthesized AuNPs were mixed with $\mathrm{KBr}$ and pellets were formed which were subjected to FT-IR 
analysis. For $\mathrm{KBr}$ pellet formation, $5 \mathrm{mg}$ each of dried extract and AuNPs were separately mixed with $100 \mathrm{mg}$ of $\mathrm{KBr}$ and condensed into pellet using hydraulic press.

\section{XRD studies}

To investigate the crystalline nature of prepared biogenic AuNPs, analysis through XRD was performed. The AuNPs suspension was washed thrice with double distilled water and collected by repeated centrifugation on a clean glass slide and measurement was made through a PANalytical X'PERT-PRO X-ray diffractometer by employing monochromatic $\mathrm{Cu} \mathrm{K} \alpha$ radiation $(1.5406 \AA)$ running at $45 \mathrm{kV}$ and $40 \mathrm{~mA}$.

\section{TEM analysis}

The stable washed AuNPs suspensions were sonicated and diluted with deionized water to get the intensity of absorbance around 0.50 a.u. and a drop of suspensions was taken on 200 mesh carbon coated copper grids (Ted pella, USA) and placed the grids for $2 \mathrm{~min}$, and removed the remaining solution with Whatman paper, and allowed the grids to dry before measurement. After drying, the particles were visualized through Hitachi H-7500 TEM instrument.

\section{Catalytic efficacy of biogenic AuNPs}

The catalytic efficacy of synthesized gold nanoparticles was examined for borohydride reduction of two anthropogenic dyes MB and Rh-B as model reaction. Initially, a $20 \mathrm{ml}$ of colloidal solution of AuNPs was centrifuged and washed thrice with double distilled water and twice with ethanol. Afterwards, the gold nanopellet obtained, was dissolved ultrasonically in $20 \mathrm{ml}$ of distilled water to make gold nanoparticles solution free from biomolecules. The degradation of each dye was studied by recording the UVVis spectrum for $2 \mathrm{~min}$. The degradation was also studied without AuNPs and $\mathrm{NaBH}_{4}$ as control reactions.

\section{Results and discussion}

The selection of fennel seeds in the present work has proven to be an inexpensive, green and innovative tool for the fabrication of stable gold nanoparticles. Figure 1 shows the brief reaction process for the preparation of AuNPs. The phytoconstituents of fennel seeds, such as polyphenols and flavonoids (such as rosmarinic acid, chlorogenic acid, quercetin and apigenin) exhibiting strong antioxidant properties, (Faudale et al. 2008) provide excess of electrons to the $\mathrm{Au}^{3+}$ ions and responsible for reduction to $\mathrm{Au}^{0}$ (AuNPs) and subsequently stabilize the AuNPs. Generally, some organic ligands or ionic surfactants are employed in the preparation of noble metal nanoparticles and are difficult to get rid of them completely from the final products which may block the active sites of catalysts. The major significance of this biomimetic procedure to fabricate the AuNPs using aqueous seeds extract is that the phytochemicals are easily separable and does not allow the formation of layers around the nanoparticles, which makes them effective catalysts. Moreover, it does not involve any external energy input, and the process occurs normally in distilled water at room temperature, making it efficient and green methodology. Further, this seed extract mediated synthesis of AuNPs highlights another advantage of this approach for the preparation of various noble metalsemiconductor nanocomposites materials.

\section{UV-Vis spectroscopy}

Figure 2a-c depicts the UV-Vis spectra for FA-1, FA-2 and FA-3. All the three systems showed an optical absorption around $550 \mathrm{~nm}$, which is significant of surface plasmon resonance (SPR) absorption of metallic $\mathrm{Au}$ nanoparticles. Further, the effect of time span of reaction between biomolecules of fennel seeds and $\mathrm{Au}^{3+}$ ions on the AuNPs synthesis was also investigated and it has been seen that intensity of peak around $550 \mathrm{~nm}$ increases with increase in time period. This enhancement in the intensity of SPR can be attributed to increase in number of nanoparticles formation. However, in case of FA-3 sample, where $30 \mathrm{ml}$ aqueous extract was added, reaction reached near completion in $2 \mathrm{~h}$ (with no shift in $\lambda_{\max }$ value), which can be attributed to increase in number of phytochemicals involved in reduction process. Figure $2 d$ depicts the UVVis spectra of FA-1(optimized concentration ratio of $\mathrm{HAuCl}_{4} \cdot 3 \mathrm{H}_{2} \mathrm{O}$ : FSE), after $24 \mathrm{~h}$ to test the stability of AuNPs. A negligible or slight shift in the intensity of absorption peak was observed, as compared with $2.5 \mathrm{~h}$ absorption peak, and no drastic change in intensity of color of solution was observed which indicates that biogenic AuNPs were stable over a period of time.

\section{TEM analysis}

The morphologies and sizes of prepared AuNPs were investigated using transmission electron microscopy (TEM) analysis. Figure 3 demonstrates typical TEM images of biosynthesized AuNPs, which depict that the AuNPs were poly dispersed and mostly spherical, while few of the particles were observed to be having irregular shapes. Such variations in morphologies and sizes of biogenic nanoparticles are quite common (Gangula et al. 2011; Choudhary et al. 2016). TEM analysis further revealed that majority of AuNPs had an average size around $18-20 \mathrm{~nm}$. For particle 
Fig. 1 Reaction process showing the formation of stable AuNPs by phytochemical reduction of $\mathrm{Au}^{3+}$ ions with fennel seeds extract

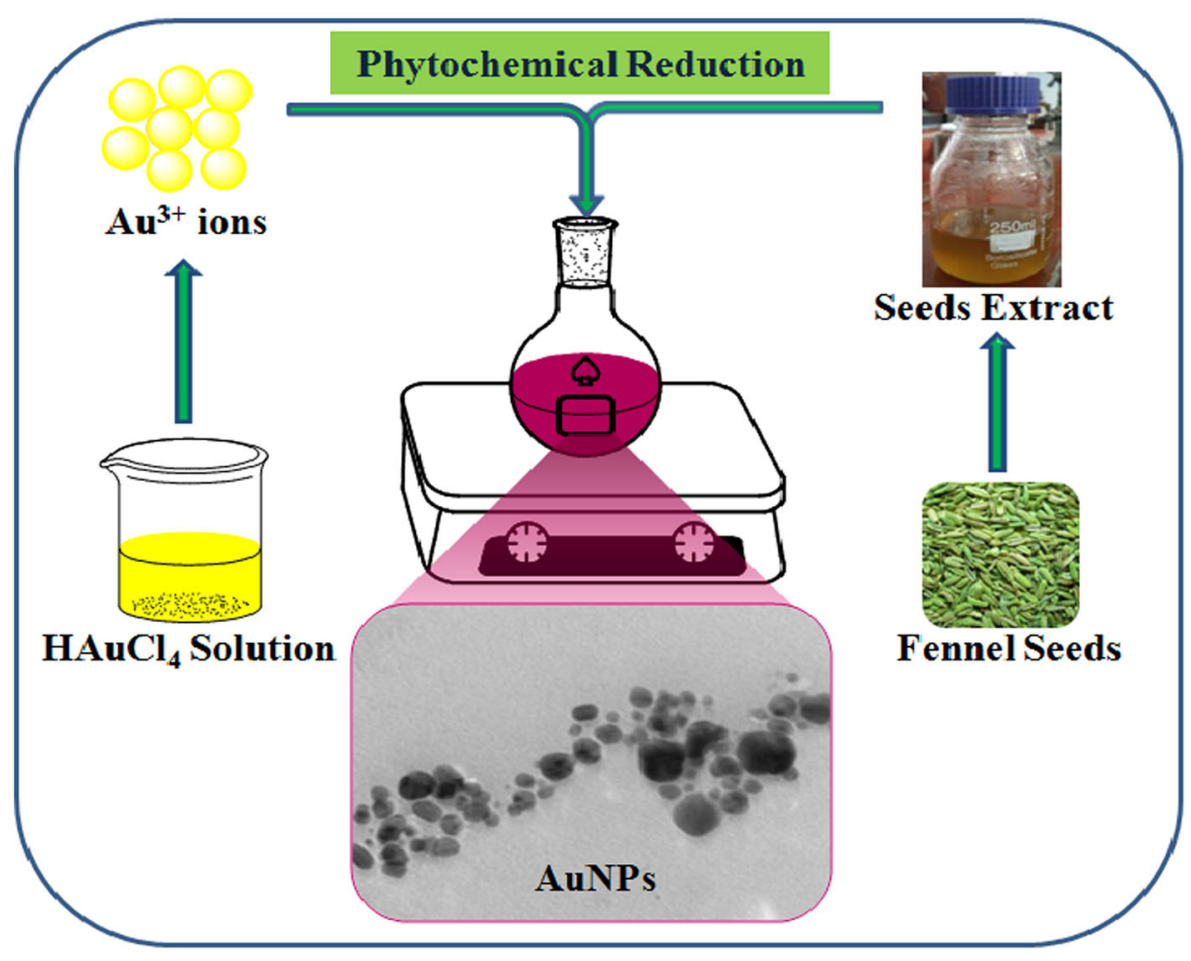

size distribution, around 120 particles were examined with ImageJ software, and a histogram was plotted (Fig. 3d). From these figures, it has been observed that the average size of particles is approximately $20 \pm 2 \mathrm{~nm}$, and the nanoparticles with sizes varying from 10 to $30 \mathrm{~nm}$ accounts for around $90 \%$ of all particles examined.

\section{X-Ray diffraction analysis}

To investigate crystalline structure of the synthesized AuNPs X-ray diffraction study was carried out. The diffraction pattern of the biosynthesized AuNPs (Fig. 4) shows five intense Bragg reflections which are indexed to face-centered cubic (fcc) lattice of gold. A comparison with JCPDS file no. 04-0784 (Lü et al. 2012) confirmed the crystalline structure of AuNPs, as confirmed by the peaks at $2 \theta$ values of $38.12^{\circ}, 44.37^{\circ}, 64.53^{\circ}, 77.39^{\circ}$ and $81.79^{\circ}$ correspond to (111), (200), (220), (311) and (222) planes, respectively. Moreover, the XRD peaks were observed to be broader at their bases, which further confirmed that the formed AuNPs were in nanorange (Ahmad et al. 2010).

\section{FT-IR spectroscopy}

The FT-IR spectrum of dried aqueous fennel seeds extract and prepared AuNPs were recorded for investigating the functional groups of phytoconstituents involved in the reduction and capping of the prepared nanoparticles (Fig. 5). The major absorbance band present in the spectrum of fennel seeds were at 3345.66, 2928.30, $2852.83,1710.19,1619.62,1455.85,1241.50,1167.54$ and $1036.23 \mathrm{~cm}^{-1}$. The broad band at $3345.66 \mathrm{~cm}^{-1}$ could be assigned to stretching of hydrogen bonded phenolic groups of phytoconstituents. The bands at 2928.30 and $2852.83 \mathrm{~cm}^{-1}$ correspond to asymmetric and symmetric stretching vibrations, respectively, of methylene groups. The bands at $1710.19,1619.62$ and $1455.85 \mathrm{~cm}^{-1}$ can be due to carbonyl $(\mathrm{C}=\mathrm{O})$, aromatic $(\mathrm{C}=\mathrm{C})$ and carboxyl $(\mathrm{O}=\mathrm{C}-\mathrm{O})$ stretching vibrations, respectively, whereas the sharp band at $1241.50 \mathrm{~cm}^{-1}$ corresponds to epoxy $(\mathrm{C}-\mathrm{O})$ ring vibrations. The bands at 1167.54 and $1036.23 \mathrm{~cm}^{-1}$ were due to the stretching vibrations of $\mathrm{C}-\mathrm{O}$ group of alkoxy and alcoholic groups, respectively. For AuNPs, the characteristic absorbance bands were observed at 3412.83, 2923.02, 1621.13, 1449.06, 1366.80 and $1046.03 \mathrm{~cm}^{-1}$, respectively. In comparison with FT-IR spectra of fennel seeds, small shifts in the absorbance bands from 3345.66 to $3412.83 \mathrm{~cm}^{-1}, 1619.62$ to $1621.13 \mathrm{~cm}^{-1}, 1455.85$ to $1449.06 \mathrm{~cm}^{-1}$ and 1036.23 to $1046.03 \mathrm{~cm}^{-1}$ were observed, which suggest the binding of hydroxyl and carboxylate groups of phytoconstituents with gold nanoparticles.

\section{Mechanism for the formation of AuNPs by phytoconstituents of fennel seeds}

To propose the mechanism of redox reaction occurring between the phytoconstituents of fennel seeds and $\mathrm{Au}^{3+}$ 

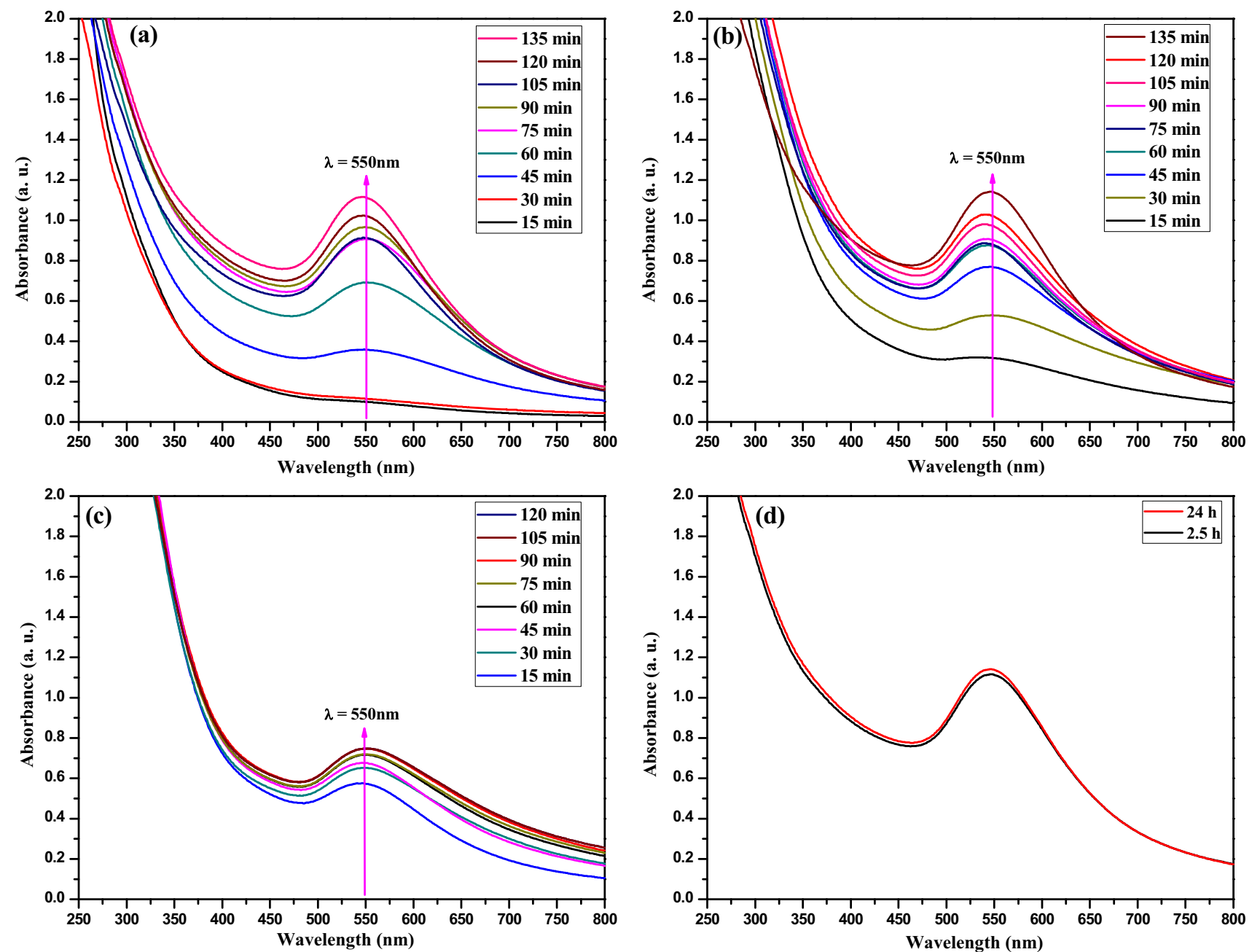

Fig. 2 The UV-Vis spectra of AuNPs synthesized with a FA-1 (9:1 v/v), b FA-2 (8:2 v/v), c FA-3 (7:3 v/v) ratios of gold solution and seeds extract, $\mathbf{d}$ spectra recorded after $24 \mathrm{~h}$, showing stability of biogenic nanoparticles

ions is very difficult, because every plant material contains diverse range of phytoconstituents with various complex molecular structures. However, an attempt has been made to discuss the process of bio-formation and stabilization of AuNPs. Generally, phytochemicals reduce the metal ions by providing excess of electrons and protect the reduced particles to aggregate by capping them. Therefore, they play a dual role. Figure 6 represents the plausible mechanism for the biogenic formation of AuNPs by active phytochemicals present in the seeds extract. The polyphenolic compounds, such as rosmarinic acid, chlorogenic acid, quercetin, and apigenin (Faudale et al. 2008), containing high density of hydroxyl groups (having common functionalities as shown in mechanism), synergistically reduce the $\mathrm{Au}^{3+}$ to $\mathrm{Au}^{0}$ with concomitant oxidation of the polyphenolic compounds to quinones. Further, collision of these $\mathrm{Au}^{0}$ nuclei with each other results in the formation of AuNPs, which can be protected from agglomeration by capping with quinones and other coordinating phytoconstituents present in the seeds extract.

\section{Catalytic activity of AuNPs for reduction of anthropogenic dye pollutants}

The catalytic reduction of methylene blue $(0.3 \mathrm{ml}-$ $250 \mu \mathrm{M})$ by $\mathrm{NaBH}_{4}(1.0 \mathrm{ml}-10 \mathrm{mM})$ was carried out using stable colloidal solution of biogenic gold nanoparticles $(0.3 \mathrm{ml})$ as catalyst. Total volume was made $3.0 \mathrm{ml}$ by adding double distilled water. Generally, methylene blue shows absorption maxima around $660 \mathrm{~nm}$ and a small shoulder around $610 \mathrm{~nm}$. After adding AuNPs to the solution of methylene blue dye and $\mathrm{NaBH}_{4}$, the intense blue color of the solution rapidly disappeared. Within 2 min, complete disappearance of blue color of MB was observed which further reflected in decrease in intensity of MB solution (Fig. 7a). Further, it was found that in the 

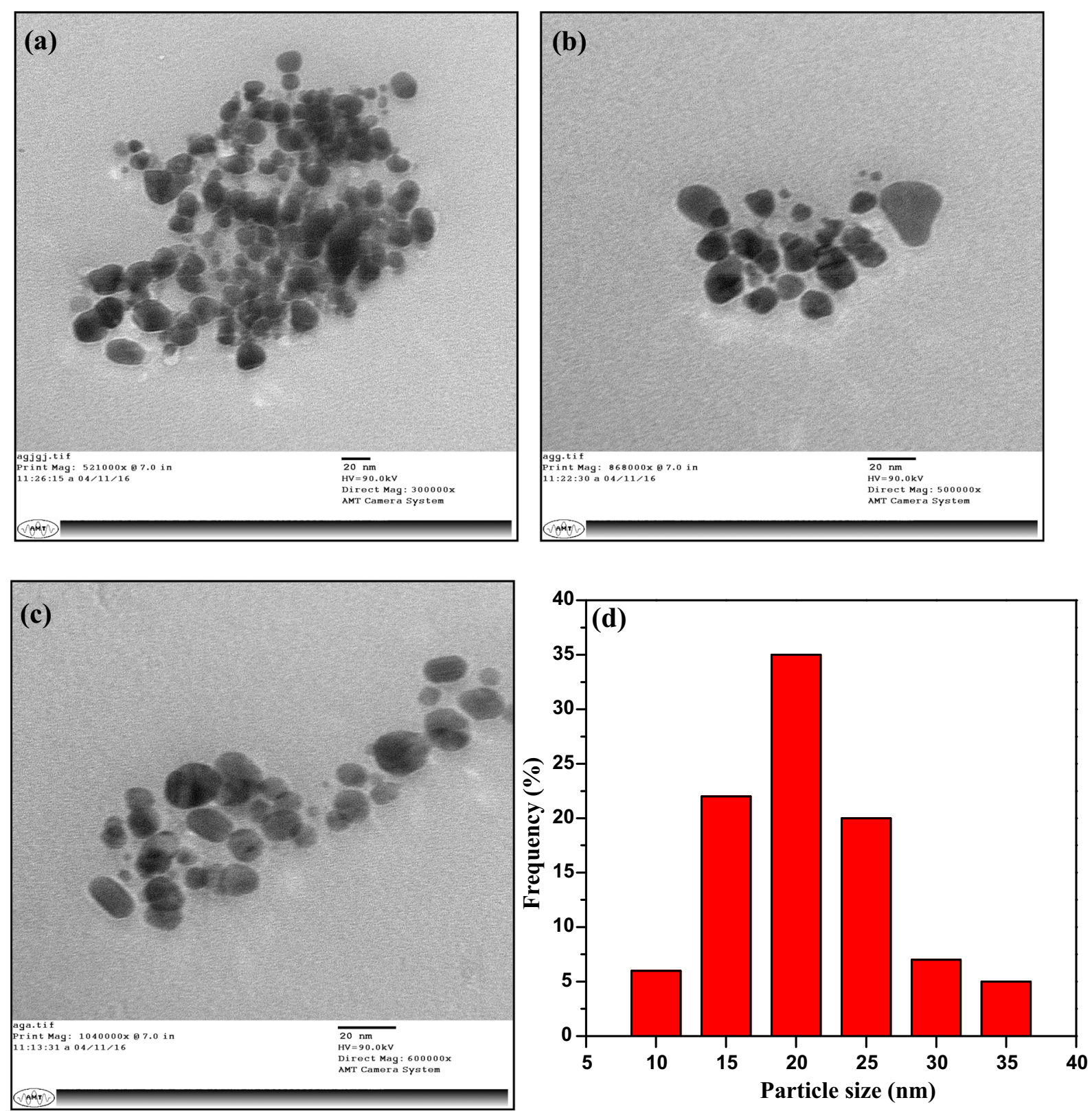

Fig. 3 TEM images (a-c) of AuNPs synthesized with (9:1 v/v) ratio of gold solution and seeds extract and $\mathbf{d}$ histogram showing the particle size distribution

absence of AuNPs, the degradation of MB did not occur. Similarly, the catalytic efficacy of synthesized gold nanoparticles $(0.3 \mathrm{ml})$ in reduction (degradation) of $(0.3 \mathrm{ml}-100 \mu \mathrm{M})$ rhodamine $\mathrm{B}(\mathrm{Rh}-\mathrm{B})$ by $\mathrm{NaBH}_{4}(1.0 \mathrm{ml}-$ $10 \mathrm{mM}$ ) was also studied at room temperature. The characteristic pink color of Rh-B and the corresponding absorption peak observed at $554 \mathrm{~nm}$ was disappeared within 2 min using $\mathrm{NaBH}_{4}$ and gold nanocatalyst. Moreover, in the absence of gold nanoparticles, $\mathrm{NaBH}_{4}$ alone was not able to degrade the $\mathrm{Rh}-\mathrm{B}$ (Fig. 7b). The reduction of anthropogenic dyes using $\mathrm{NaBH}_{4}$ alone, in the absence of gold nanocatalysts did not occur, due to the kinetic barrier. Similar results for the degradation of dyes have been reported using palladium nanoparticles (Kora and Rastogi 2016).

This ultra-rapid catalytic activity of biogenic gold nanoparticles towards the degradation of dye pollutants can be explained on the basis of adsorption behavior of dye molecules onto the metal nanoparticles. As discussed earlier that ionic surfactants employed in the preparation of noble metal nanoparticles make insulating layer around them and block the active sites of catalysts, and thereby affect the accessibility of reacting molecules to reach metal particles (Jana et al. 2000). Therefore, a large decrease in 


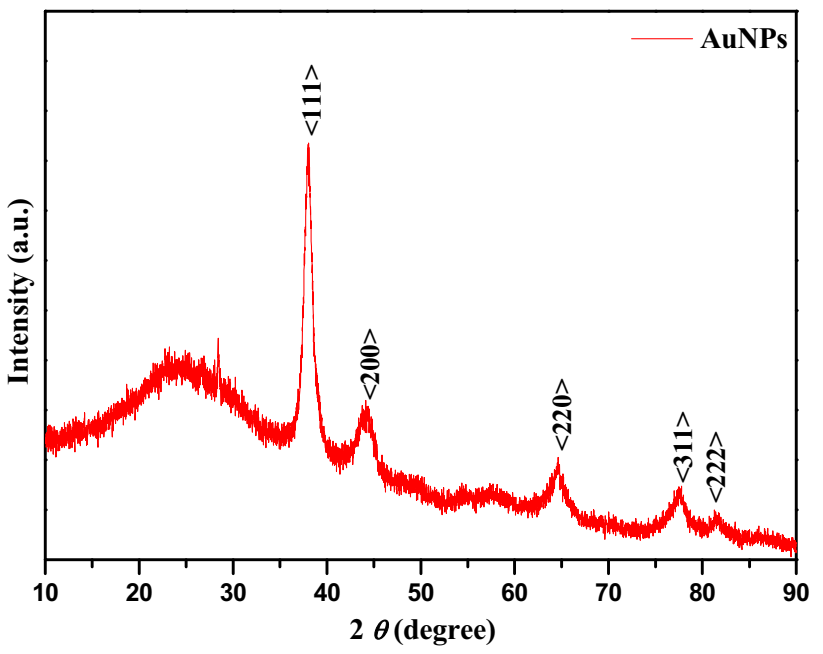

Fig. 4 X-ray diffraction pattern of synthesized AuNPs using fennel seeds extract

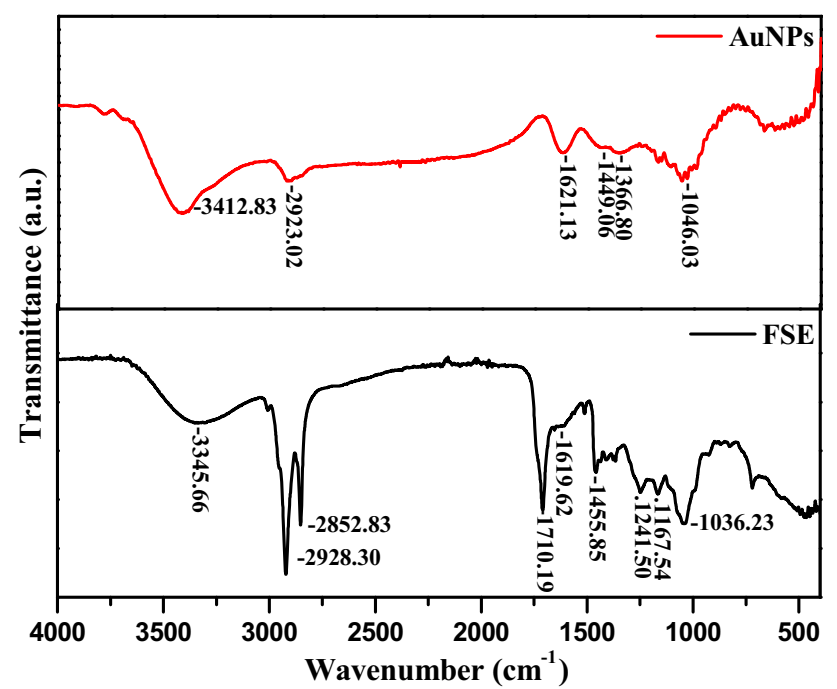

Fig. 5 FT-IR spectra of dried aqueous extract of fennel seeds and stabilized AuNPs the rate of reaction is observed. However, the biomolecules are easily separable and does not allow the formation of layers around the nanoparticles and make them efficient catalysts. Further, a metal catalyzed reduction/degradation process can be easily discussed by electrochemical mechanism, in which the metal nanoparticles act as electron relay for reductant and oxidant. When the dye molecules and $\mathrm{BH}_{4}{ }^{-}$ions are in close proximity, they get adsorbed on the surface of metal particles and electron transfer from $\mathrm{BH}_{4}{ }^{-}$ions to dye molecules occurs via AuNPs (Jiang et al. 2005). $\mathrm{BH}_{4}^{-}$ions first provide electrons to AuNPs and produce a negatively charged layer around them, as shown by reaction (1).

$$
\begin{aligned}
\mathrm{BH}_{4}^{-}+\text {AuNPs }+3 \mathrm{H}_{2} \mathrm{O} \rightarrow & \mathrm{BO}_{3}^{3-}+(\mathrm{AuNPs})^{8-} \\
& +10 \mathrm{H}^{+}
\end{aligned}
$$

Therefore, the electron cloud around biogenic gold nanoparticles is easily accessible to the dyes and accordingly no induction period is observed as compared to surfactant stabilized nanoparticles (Fig. 8).

\section{Conclusion}

A facile, biomimetic and environment friendly procedure for the preparation of stable gold nanoparticles (AuNPs) was described using aqueous extract of fennel (Foeniculum vulgare) seeds. The bioreduction of gold ions to crystalline nanoparticles with an average size of $20 \pm 2 \mathrm{~nm}$ and subsequent capping was mediated by polyphenolic compounds of fennel seeds. Further, these surfactant free biogenically prepared gold nanoparticles showed an excellent catalytic activity towards the degradation of anthropogenic dye pollutants. Hence, the efficient dye degradation efficacy of biogenic AuNPs can have wide applications in environment remediation of waste water polluted with toxic synthetic dyes and pigments.

Fig. 6 Plausible mechanism for formation and stabilization of AuNPs by phytoconstituents of fennel seeds

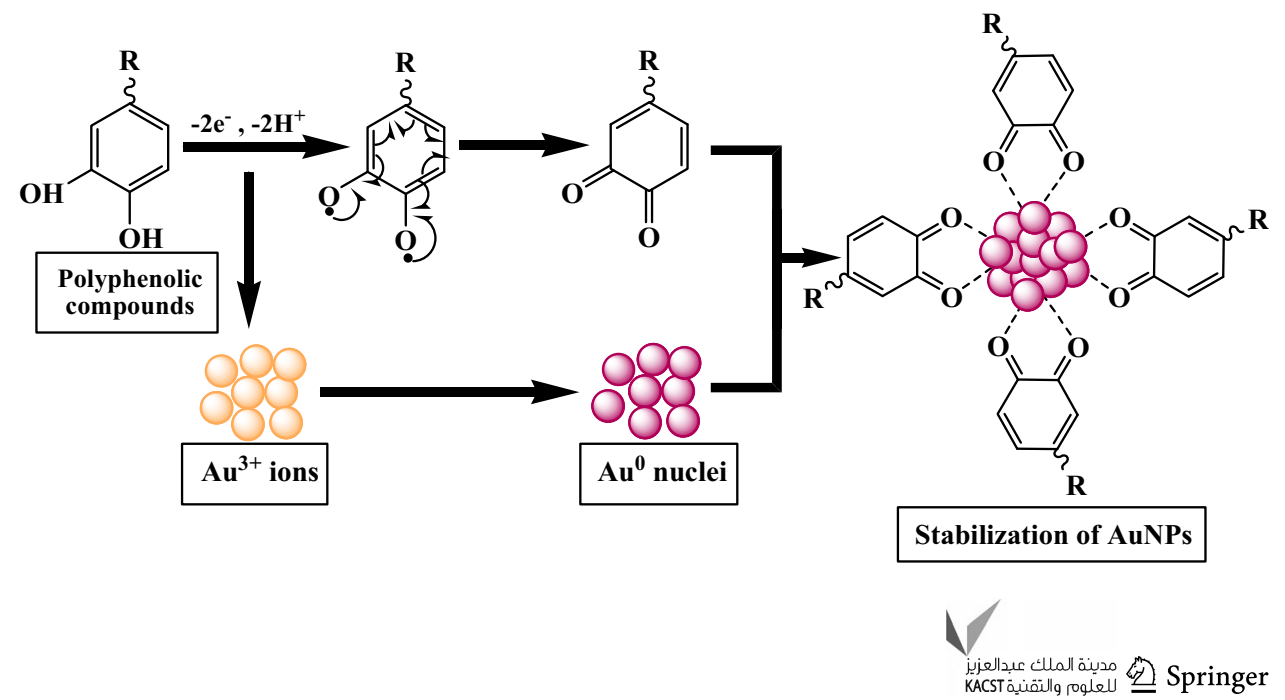



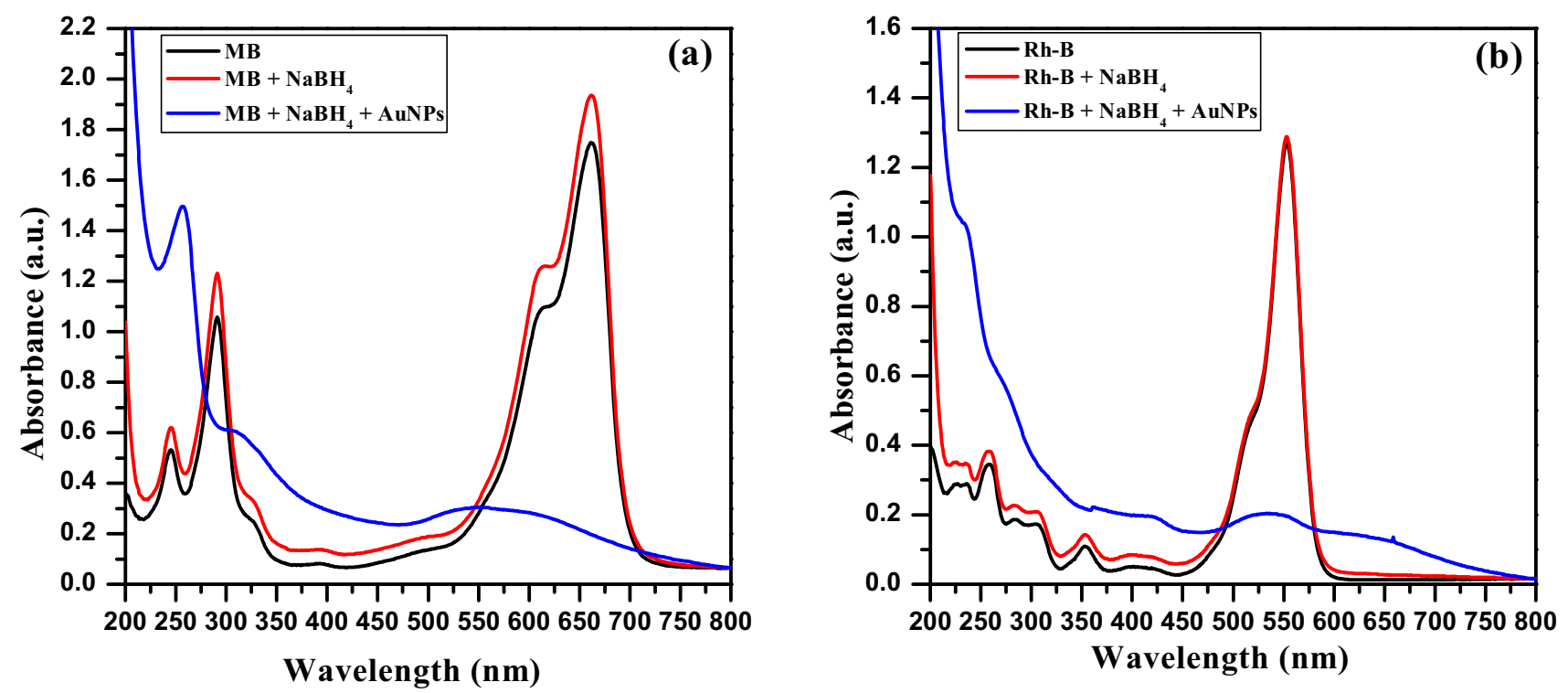

Fig. 7 The UV-Vis spectra of decolorization of dyes by $\mathrm{NaBH}_{4}$ using AuNPs as catalyst at 2 min. a Methylene blue, $\mathbf{b}$ rhodamine $\mathrm{B}$

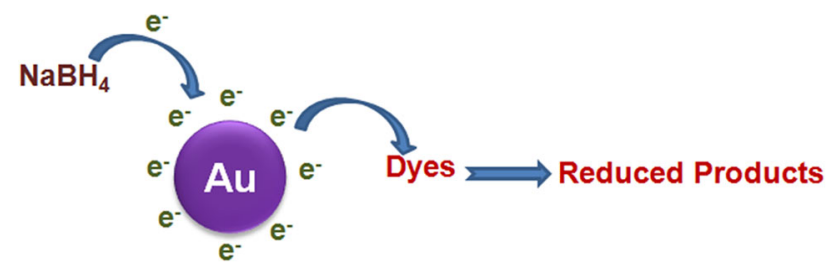

Fig. 8 Proposed mechanism for the catalytic reduction of $\mathrm{MB}$ and Rh-B by $\mathrm{NaBH}_{4}$ in the presence of AuNPs into respective reduced products

Acknowledgements The work is supported by Northern Regional College Bureau, University Grants Commission (NRCB-UGC) New Delhi, under minor research project scheme [F. 8-4 (107)/2015(MRP/ NRCB)]. MKC would like to thank Principal and Management of Guru Nanak National College, Doraha (Ludhiana), Punjab, for their constant support, encouragement and providing required infrastructure and laboratory facilities for smoothly carry out the research work. We are also grateful to the SAIF, Panjab University, Chandigarh and Thapar University, Patiala for extending the TEM and XRD facilities, respectively.

\section{Compliance with ethical standards}

Conflict of interest The authors declare no competing financial interest.

Open Access This article is distributed under the terms of the Creative Commons Attribution 4.0 International License (http:// creativecommons.org/licenses/by/4.0/), which permits unrestricted use, distribution, and reproduction in any medium, provided you give appropriate credit to the original author(s) and the source, provide a link to the Creative Commons license, and indicate if changes were made.

\section{References}

Ahmad N, Sharma S, Alam MK et al (2010) Rapid synthesis of silver nanoparticles using dried medicinal plant of basil. Colloids Surf B Biointerfaces 81:81-86. doi:10.1016/j.colsurfb.2010.06.029

American Pharmacists Association (2012) Risk of methemoglobinemia in the medicine cabinet. Pharm Today 18:58

Badgujar SB, Patel VV, Bandivdekar AH (2014) Foeniculum vulgare Mill: a review of its botany, phytochemistry, pharmacology, contemporary application, and toxicology. Biomed Res Int 2014:1-33. doi:10.1155/2014/842674

Choudhary MK, Kataria J, Cameotra SS, Singh J (2016) A facile biomimetic preparation of highly stabilized silver nanoparticles derived from seed extract of Vigna radiata and evaluation of their antibacterial activity. Appl Nanosci 6:105-111. doi:10. 1007/s13204-015-0418-6

Faudale M, Viladomat F, Bastida J et al (2008) Antioxidant activity and phenolic composition of wild, edible, and medicinal fennel from different Mediterranean countries. J Agric Food Chem 56:1912-1920. doi:10.1021/jf073083c

Forster S, Thumser AE, Hood SR, Plant N (2012) Characterization of rhodamine-123 as a tracer dye for use in in vitro drug transport assays. PLoS One 7:1-9. doi:10.1371/journal.pone.0033253

Gangula A, Podila R, Rao M et al (2011) Catalytic reduction of 4-nitrophenol using biogenic gold and silver nanoparticles derived from breynia rhamnoides. Langmuir 27:15268-15274. doi:10.1021/la2034559

Hardy RA, Pates JM, Quinton JN, Coogan MP (2016) A novel fluorescent tracer for real-time tracing of clay transport over soil surfaces. CATENA 141:39-45. doi:10.1016/j.catena.2016.02. 011

Jana NR, Wang ZL, Pal T (2000) Redox catalytic properties of palladium nanoparticles: surfactant and electron donor-acceptor effects. Langmuir 16:2457-2463. doi:10.1021/la990507r

Jiang ZJ, Liu CY, Sun LW (2005) Catalytic properties of silver nanoparticles supported on silica spheres. J Phys Chem B 109:1730-1735. doi:10.1021/jp046032g 
Kalaiselvi A, Roopan SM, Madhumitha G et al (2015) Synthesis and characterization of palladium nanoparticles using Catharanthus roseus leaf extract and its application in the photo-catalytic degradation. Spectrochim Acta Part A 135:116-119

Kant R (2012) Textile dyeing industry an environmental hazard. Nat Sci 4:22-26. doi:10.4236/ns.2012.41004

Kora AJ, Rastogi L (2016) Catalytic degradation of anthropogenic dye pollutants using palladium nanoparticles synthesized by gum olibanum, a glucuronoarabinogalactan biopolymer. Ind Crop Prod 81:1-10. doi:10.1016/j.indcrop.2015.11.055

Kumari AS, Venkatesham M, Ayodhya D, Veerabhadram G (2015) Green synthesis, characterization and catalytic activity of palladium nanoparticles by xanthan gum. Appl Nanosci 5:315-320. doi:10.1007/s13204-014-0320-7

Lü X, Song Y, Zhu A et al (2012) Synthesis of gold nanoparticles using cefopernazone as a stabilizing reagent and its application. Int J Electrochem Sci 7:11236-11245

Mull DS (1993) Use of dye tracing to determine the direction of ground-water flow in karst terrane at the Kentucky state University research farm near frankfort, Kentucky. US Geol Surv Water-Resour Investig Rep 93-4063:1-21

Mwangi VI, Mumo RM, Kiboi DM et al (2016) Methylene blue inhibits lumefantrine-resistant Plasmodium berghei. J Infect Dev Ctries 10:635-642. doi:10.3855/jidc.7556

Narayanan KB, Park HH, Sakthivel N (2013) Extracellular synthesis of mycogenic silver nanoparticles by Cylindrocladium floridanum and its homogeneous catalytic degradation of 4-nitrophenol. Spectrochim Acta Part A 116:485-490. doi:10.1016/j. saa.2013.07.066

Purkayastha S, Narain R, Dahiya P (2012) Evaluation of antimicrobial and phytochemical screening of Fennel, Juniper and Kalonji essential oils against multi drug resistant clinical isolates. Asian Pac J Trop Biomed 2:S1625-S1629. doi:10.1016/S22211691(12)60465-1

Rajesh CS, Anjana R, Sreeroop SS, Kartha CS (2014) Reflection mode holographic recording in methylene blue-sensitized polyvinyl alcohol acrylamide films. Pramana J Phys 82:259-264. doi:10.1007/s12043-013-0673-6
Roby MHH, Sarhan MA, Selim KAH, Khalel KI (2013) Antioxidant and antimicrobial activities of essential oil and extracts of fennel (Foeniculum vulgare L.) and chamomile (Matricaria chamomilla L.). Ind Crops Prod 44:437-445. doi:10.1016/j.indcrop. 2012.10.012

Roopan SM, Rohit Madhumitha G et al (2013) Low-cost and ecofriendly phyto-synthesis of silver nanoparticles using Cocos nucifera coir extract and its larvicidal activity. Ind Crops Prod 43:631-635. doi:10.1016/j.indcrop.2012.08.013

Sadowski Z, Maliszweska IH, Grochowalaska B et al (2008) Synthesis of silver nanoparticles using microorganisms. Mater Sci Poland 26:419-424

Sahoo GP, Kumar Bhui D, Das D, Misra A (2014) Synthesis of anisotropic gold nanoparticles and their catalytic activities of breaking azo bond in sudan-1. J Mol Liq 198:215-222. doi:10. 1016/j.molliq.2014.06.032

Schirmer RH, Coulibaly B, Stich A et al (2003) Methylene blue as an antimalarial agent. Redox Rep 8:272-275. doi:10.1179/ 135100003225002899

Shelley WB (1969) Fluorescent staining of elastic tissue with Rhodamine $\mathrm{B}$ and related xanthene dyes. Histochemie 20:244-249. doi:10.1007/BF00306012

Temmerman K, Nickel W (2009) A novel flow cytometric assay to quantify interactions between proteins and membrane lipids. J Lipid Res 50:1245-1254. doi:10.1194/jlr.D800043-JLR200

Umadevi M, Bindhu MR, Sathe V (2013) A novel synthesis of malic acid capped silver nanoparticles using Solanum lycopersicums fruit extract. J Mater Sci Technol 29:317-322. doi:10.1016/j. jmst.2013.02.002

Vijayakumar M, Priya K, Nancy FT et al (2013) Biosynthesis, characterisation and anti-bacterial effect of plant-mediated silver nanoparticles using Artemisia nilagirica. Ind Crops Prod 41:235-240. doi:10.1016/j.indcrop.2012.04.017

Yang T, Du M, Zhang M et al (2015) Synthesis and immobilization of Pt nanoparticles on amino-functionalized halloysite nanotubes toward highly active catalysts. Nanomater Nanotechnol 5:1. doi: $10.5772 / 60112$ 